\title{
EDITORIAL
}

\section{PANDEMIC AND ROLE OF MEDIA}

The year 2020 has witnessed turbulent times across the globe due to the declaration of Pandemic - COVID-19 by the World Health Organization (WHO). On 11 March 2020, WHO Director-General's opening remarks at the media briefing on COVID-19 explained the fact to the world that this novel Corona Virus could be characterized as a pandemic and announced the alarming levels of spread and its severity. The gravity of the scenario was appraised to the entire nations that it should not be taken as carelessly and warned about the aftermaths of this pandemic. The disease was initiated from the city of Wuhan, China and later spread to South Korea, the United States and Europe, which witnessed the challenges these developed nations faced. The world saw that how these developed nations altered their ways and means from the aftermath of this severe pandemic to the lives of their citizens. Since the developing nations and underdeveloped nations were yet to see the fate of COVID-19 after February, many nations, including India, announced serious measures like complete Lockdown. Prime Minister Narendra Modi announced a complete lockdown for India for 21 days with effect from 24 March 2020, which continued till 31 May 2020 and the economy was made open in a phased manner from June 2020. India witnessed the strongest measure of complete Lockdown in the world due to the second-highest populated country in the world and only essential services were open in this critical phase.

In this background of the pandemic, where only the essential services were open during the phase of complete Lockdown, the media was the one who took the lead and appraised day-to-day progress reports to the entire citizens of India. Entire Indians were simply glued to the Television networks and social media platforms for getting the happenings of the nation and world outside. The pandemic not only brought measures like Work from Home, Social Distancing, Wearing Masks, Washing Hands, Sanitization, Maintaining Hygiene, but also affected the well-being of citizens of all nations. Entire Media networks and journalists came to the forefront and reported the news amidst this pandemic in the presence of COVID-19. The functioning of government officials, police personnel, doctors, health workers and media networks becomes the integral functioning of the economies of nations. India witnessed vital announcements and advisories by our Prime Minister, Governor of Reserve Bank of India, Finance Minister of India, Health Minister and various Chief Ministers of States through media channels. Various campaigns were announced throughout the phase of lockdown and post lockdown phase to engage and channelize the citizens of India. Indians also engaged themselves into different activities and posted them on social media platforms like Facebook, Twitter, LinkedIn, YouTube, and gets connected with the others online. The most interesting aspect which came out in this online scenario during the pandemic was in the Education sector, where the classes were held online, and technology played an important role into the same. People explored different technology platforms to interact online, and education was shifted entirely on unexplored yet existing platforms like Zoom, Google Meet, CISCO Webex. The education industry further strengthened itself with big Universities shifting to strong platforms like, Blackboard and Microsoft Teams to engage blended learning systems into operation. These platforms enabled two-way communication among the teacher and the taught and gave new dimensions to the education sector.

The different world brought many challenges to the lives of individuals, where economies of many nations saw decline in growth rates, unemployment due to job losses, salary downgrades, and especially the mass labor migration which people saw on media networks. The individual well-being and economic well-being of nations dipped to new lows and tried their best to come out of the same in the first half of the year 2020. The only ray of hope was expected from the researchers across the nation to invent a vaccine to cure human lives out of this severe pandemic, which people witnessed after 100 years of Spanish flu. This backdrop of pandemic initiated research across the world to write on the area of COVID-19 and its impact on the 
economic slowdown, financial markets, wellbeing, COVID-19 Vaccine, measures to safeguard the human beings from COVID-19. Social media, which provided diverse communication channels to the people also gave rise to the qualitative research in this year 2020. In December, the recent news of some successful vaccines with a success rate of 70 percent to 95 percent from countries like Russia, UK, USA and the process of immunization gave a sign of relief to the world and Indian being the largest populated nation is still waiting for the largest vaccination process of the world.

Journal of Content, Community and Communication (JCCC) always try to cover the emerging issues which touch the lives of its avid readers and thereby announced the theme on "Media and COVID-19". The subthemes covered the media landscape around the world and India's Media Industry during the pandemic times on account of COVID-19. Another dimension to be covered in December 2020 issue was the impact of social media, OTT platforms, fake news and myths related to COVID-19. The December 2020 issue encouraged the researchers across the globe to submit their manuscripts which covered not only quantitative studies in the domain of media studies but also qualitative research studies emerged during the pandemic times in the world. The launch of the theme was well accepted by the writers across the nations and we received $250+$ manuscripts, and editorial board selected quality manuscripts covering the topic of Media, COVID-19 on both qualitative and quantitative research. To highlight some of the top articles in this issue of JCCC, papers like 'New Education Policy, 2020: Qualitative (Contents) Analysis and Twitter Mining (Sentiment Analysis)' covered the qualitative data analysis techniques to understand critical areas of focus of policy documents and computer-assisted qualitative data analysis software to address three crucial aspects of the policy - course, language, and students, for the higher education sector under New Education Policy of India. Another manuscript on Empirical Examination of the Adoption of Zoom Software during Covid-19 Pandemic: Zoom TAM covered an integrated model of adoption of Zoom platform by the teachers for conducting the virtual meeting/lectures in education institutes during the current COVID-19 pandemic situation by Partial Least Square Structure Equation Modelling (PLS-SEM) in SmartPLS version 3.3.2. Further, manuscripts on 'Students' Perception on Digital Learning during Lockdown Period in India: An Empirical Study of Rural and Urban Community' provided problems faced by the students in digital learning. The issue covered the topic of Media Exaggeration and information credibility: Qualitative Analysis of fear generation for COVID- 19 using NVIVO and presented the respondents sentiment regarding the information which they received during pandemic times. The selected articles include bibliometric analysis on job-stress using visualizing network and student perceived employability with reference to media studies. Some of the interesting manuscripts included Information Processing - Heuristic versus Systematic and Susceptibility of Sharing COVID-19 related Fake News on Social Media. The study presents a research model to identify the influence of select variables on information processing and the susceptibility to falling prey to fake news on social media and contributes to the domain to media studies.

The present issue covered topics like \#Me Too Movement: Influence of Social Media Engagement on Intention to Control Sexual Harassment against Women to enhance awareness about the sex-based crimes could be increased with the participation in these kinds of social movements which in turn leads to the formation of intention to control sexual harassment against women. Pandemic had a worse effect on the theatre, which were completely closed and gave way to new platform like OTT, which were duly covered by the manuscript like "Acceptance of OTT Video Streaming Platforms in India during COVID -19: Extending UTAUT2 With content availability'. These manuscripts gave an absolutely new dimension to the research manuscripts in the field of media studies where PLS - SEM on SmartPLS software and Qualitative research on NVIVO software were comprehensively used to provide in-depth insight on research findings to the prospective readers of this Journal. The observation based research papers on 'PM Narendra Modi's Appeal on Fighting against Covid-19: A Study' covered content analysis of Mann ki Baat episodes (March-June 2020) based on the COVID-19 information and all those appeals 
to the nation that PM made in the 4 months (March -June 2020). The paper outlines the scope of understanding how PM has inculcated the habit among people about taking precautions to prevent themselves from COVID-19. Another interesting manuscript selected in this December issue was 'Assessing Job preferences of Media and Communication students in the COVID era: A conjoint analysis' and explored job attribute preferences of students in the media and communication stream during the pandemic situation. Besides these papers, other research papers covered interesting theme of the 2020 in terms of Citizen Amendment Act in India and role of civil society in health communication.

We hope that the December 2020 issue of Journal of Content, Community and Communication will be an interesting read for its avid readers and the select theme proves to important guidelines to upcoming research in the area of Media Studies and Management in social sciences. The year 2020 had been a very difficult times for many across the globe, but has also provided new opportunity for many where technology has made life easy. The lifestyle and habits of people have changed altogether in the new normal after lockdown, where health and hygiene is considered to be supreme over other priorities in human lives. The concept of Work from Home (WFH) in Technology oriented industry, Online Teaching-Learning process in the education sector, OTT replacing Theatre, Sanitization, social distancing has been the new normal and will remain ahead till the complete vaccination process is complete in India or even after the same. The process of vaccination has started in many countries and some side-effects are also reported but it is expected that human lives will be safe again in the near future for sure. With this, we will like to end our Editorial with a positive quote

Don't Let Viruses Win all the Time, Let's Beat the Coronavirus Together

\section{Dr. Sumit Narula}

Director and Associate Professor, Amity School of Communication, Amity University Gwalior

\section{Dr. Atul Shiva}

Assistant Professor in Management University School of Business, Chandigarh University, Mohali, India 